\title{
Design of a Small-Scale Supercritical Water Oxidation Reactor. Part I: Experimental Performance and Characterization
}

Stuart J. Moore ${ }^{a}$,Brian R. Pinkard ${ }^{a}$, Anmol L. Purohit ${ }^{a}$, John A. Misquith ${ }^{a}$, John C. Kramlich ${ }^{a}$, Per G. Reinhall ${ }^{a}$, Igor V. Novosselov ${ }^{a, b *}$

${ }^{a}$ University of Washington, Mechanical Engineering Department, Seattle, WA 98195

${ }^{\mathrm{b}}$ University of Washington, Institute for Nanoengineered Systems, Seattle, WA 98195

*Corresponding Author: ivn@uw.edu; +1 206 543-5248 


\begin{abstract}
A small-scale supercritical water oxidation reactor is designed and fabricated to study the destruction of hazardous wastes. The downward bulk flow is heated with the introduction of pilot fuel (ethanol/water mixture), and oxidant $\left(\mathrm{H}_{2} \mathrm{O}_{2} /\right.$ water mixture). Both streams are introduced coaxially. The fuel dilution is varied from 2 to $7 \mathrm{~mol} \%$ ethanol/water, and the oxidant-to-fuel stoichiometric equivalence ratio $\left(\Phi_{\mathrm{AF}}\right)$, is varied from 1.1 to 1.5. Higher ethanol concentrations in the pilot fuel stream and operation near-stoichiometric results in a more stratified temperature profile, i.e., highest local fluid temperatures near the top and the lowest temperatures at the bottom of the reactor. Steady operation at $603.5^{\circ} \mathrm{C}$ is achieved with a nominal residence time of $25.3 \mathrm{~s}$ at $7 \mathrm{~mol} \%$ fuel dilution and $\Phi_{\mathrm{AF}}$ of 1.1 . At the lowest pilot fuel dilution ( $\left.2 \mathrm{~mol} \%\right)$, the temperature profile is nearly uniform, approaching a distributed reaction regime.

Keywords: Supercritical Water, Oxidation, Waste Destruction, Process Engineering, Reactor Design
\end{abstract}




\section{Introduction}

Supercritical water $(\mathrm{SCW})$ is a unique reaction medium amenable to rapid destruction of wet wastes. At the elevated temperatures and pressures around and above the critical point $\left(374^{\circ} \mathrm{C}\right.$, 22.1 MPa), the physical properties of water change drastically, with a tunable density and viscosity similar to a dense vapor phase. The ion product of water drops across the critical region so that water transitions from a polar to a nonpolar solvent. Organic compounds become miscible within SCW and quickly oxidize without mass transfer limitations. Yet, inorganic acids and salts do not dissociate in the SCW environment, leading to significant issues with corrosion and scaling.

Supercritical water oxidation (SCWO) has been validated as an effective process for the destruction of wet wastes, such as sewage sludge, ${ }^{1-5}$ industrial wastewaters, ${ }^{6-9}$ and chemical warfare agent (CWA) hydrolysates. ${ }^{10-15} \mathrm{SCWO}$ converts wastes to $\mathrm{CO}_{2}, \mathrm{H}_{2} \mathrm{O}, \mathrm{N}_{2}$, salts, acids, and metal oxides, without producing $\mathrm{NO}_{x}, \mathrm{SO}_{2}$, or airborne particulate matter.

Aside from a few notable examples, attempts to commercialize the SCWO process have been hindered by the need to simultaneously solve the significant technical challenges of (i) reactor control, (ii) corrosion, (iii) plugging / scaling, (iv) component / hardware costs, and (v) process economics, considering the value of the waste destruction service. Multiple efforts to use SCWO for the destruction of sewage sludge have led to several failed commercialization efforts, largely due to some combination of the challenges listed above. A notable example is the inadvertent blowout of an expansion tank on SuperWater Solutions Inc.'s test reactor, hosted at the City of Orlando's Iron Bridge treatment plant. ${ }^{16}$ Subsequent efforts to use SCWO for biosolid disposal are facing commercial and technical challenges. ${ }^{17}$ 
A more promising application for SCWO technology is the destruction of recalcitrant, hazardous wastes, such as CWA hydrolysates or industrial effluents. Process economics tend to be better, but such wastes have high quantities of salts and heteroatoms, and inconsistent or unknown heating values, exacerbating issues of reactor control, corrosion, and plugging. To implement SCWO for hazardous waste destruction, several elegant corrosion and plugging control strategies have been proposed (e.g., transpiring wall, lined reactor), which typically require wellcharacterized system performance. ${ }^{15,18-20}$ Additionally, automated reactor control requires a thorough understanding of system dynamics and performance under a wide range of conditions for safe thermal management.

Current commercial deployments of SCWO technologies are shipping-container-sized systems or larger, with waste flow rates $>3$ gallons per minute (GPM). Systems of this size are capital intensive, requiring high waste throughputs to justify the expenditure, and thus do not serve small-volume waste producers. Often the ideal hazardous waste feedstocks for SCWO are those of relatively small volume that are expensive or dangerous to ship to a central processing facility. Small-scale producers would benefit from a small, low-cost SCWO system that can be deployed and operated on-site.

The high SCWO temperatures $\left(400{ }^{\circ} \mathrm{C}\right.$ to $\left.650{ }^{\circ} \mathrm{C}\right)$ require large systemic energy inputs. Heating of the reactor section is typically accomplished by a combination of (i) external heating (e.g., with a radiant furnace), (ii) internal heating from the fuel value of the feedstock, and/or (iii) internal heating with a pilot fuel (e.g., diesel, ethanol, isopropanol, etc.). ${ }^{21}$ Note that "pilot" can also be considered as co-fuel; the need for its use depends on the heating value of the waste stream. For example, the reactor can operate (i) without the addition of any pilot fuel for high heating value reagents, e.g., sewage sludge, (ii) with some pilot fuel used to provide flame stability, or (iii) use 
pilot/co-fuel as a primary source of the heat to reach SCWO regime. Preheating the reactor inlets with resistive or radiant heaters is common for most SCWO systems to generate the temperatures required to ensure ignition and continuous autothermal operation. Heat recovery can improve overall process efficiency but cannot eliminate the high energy input needed.

The use of pilot fuel can be challenging, as viable pilot fuels typically have characteristic reaction times that are much shorter than that of the waste being destroyed. Poorly tuned injection flow profiles or high local fuel concentrations can create dangerously hot zones within the reactor and high thermal gradients. Computational fluid dynamics (CFD) simulations can be used to design a well-controlled SCWO reactor operating with a pilot fuel. The accuracy of CFD simulations must, however, be verified through experimental testing, especially when one or more of the reactor inlets is a subcritical fluid, as the transition of a fluid across the critical point and the inter-phase behavior are challenging to model.

Downflow reactor designs have been explored for gaseous combustion systems and SCWO reactors. Buoyancy stabilized inverted gravity flames reactors (IGFR) are known for their stability and high residence times $\left(\tau_{\text {res }}\right)$ compared to upright flame configurations. The IGFR allow for control of residence times by altering the balance of the convective and buoyant terms. ${ }^{22}$ These system characteristics have been leveraged for material synthesis and studies of particle formation and growth in dilute low temperature flames. ${ }^{23-25}$ While some hydrothermal flame reactors are operated in the upright configuration, ${ }^{26}$ these provide high flame temperatures but very low residence time. Most SCWO reactors utilize the downflow arrangement ${ }^{5,12,27-29}$ to achieve long residence times and uniform temperature profiles needed for hazardous waste destruction. 
This paper characterizes the performance of a small-scale downflow SCWO reactor, operating with ethanol as a pilot fuel, and with $\mathrm{H}_{2} \mathrm{O}_{2}$ as the oxidant source. Extensive thermal characterization of the reactor at varied fuel dilution and preheating temperatures lends the insight required for stable operating conditions, SCWO combustion behavior, and strategies for reactor instrumentation and control. The reactor behavior characterized here is generalizable to other downflow SCWO reactors operating with a pilot fuel; the temperature profiles achieved with this reactor configuration should be obtainable in downflow SCWO reactors operated with similar hydrodynamic parameters. Additionally, the experimental data are used to validate the accuracy of numerical CFD simulations, which are presented and discussed in the joint manuscript.

\section{Materials and Methods}

\section{Experimental Apparatus.}

The SCWO reactor characterized in this study consists of two influent lines: (i) ethanolwater mixture, and (ii) $\mathrm{H}_{2} \mathrm{O}_{2}$-water mixture. HPLC pumps continuously introduce the influents into the reactor, with individually selectable mass flow rates. Only water is run through the system during preheating; once the desired temperatures for ignition are reached, the ethanol and $\mathrm{H}_{2} \mathrm{O}_{2}$ are introduced by switching three-way solenoid valves on the pump inlet lines. Both reactor influents lines are preheated by resistive cartridge heaters before injection into the reactor through a custom, co-flow nozzle. No ethanol degradation is expected during preheating within the fuel line. ${ }^{30}$ Figure 1 shows a high-level schematic of the SCWO reactor system. 


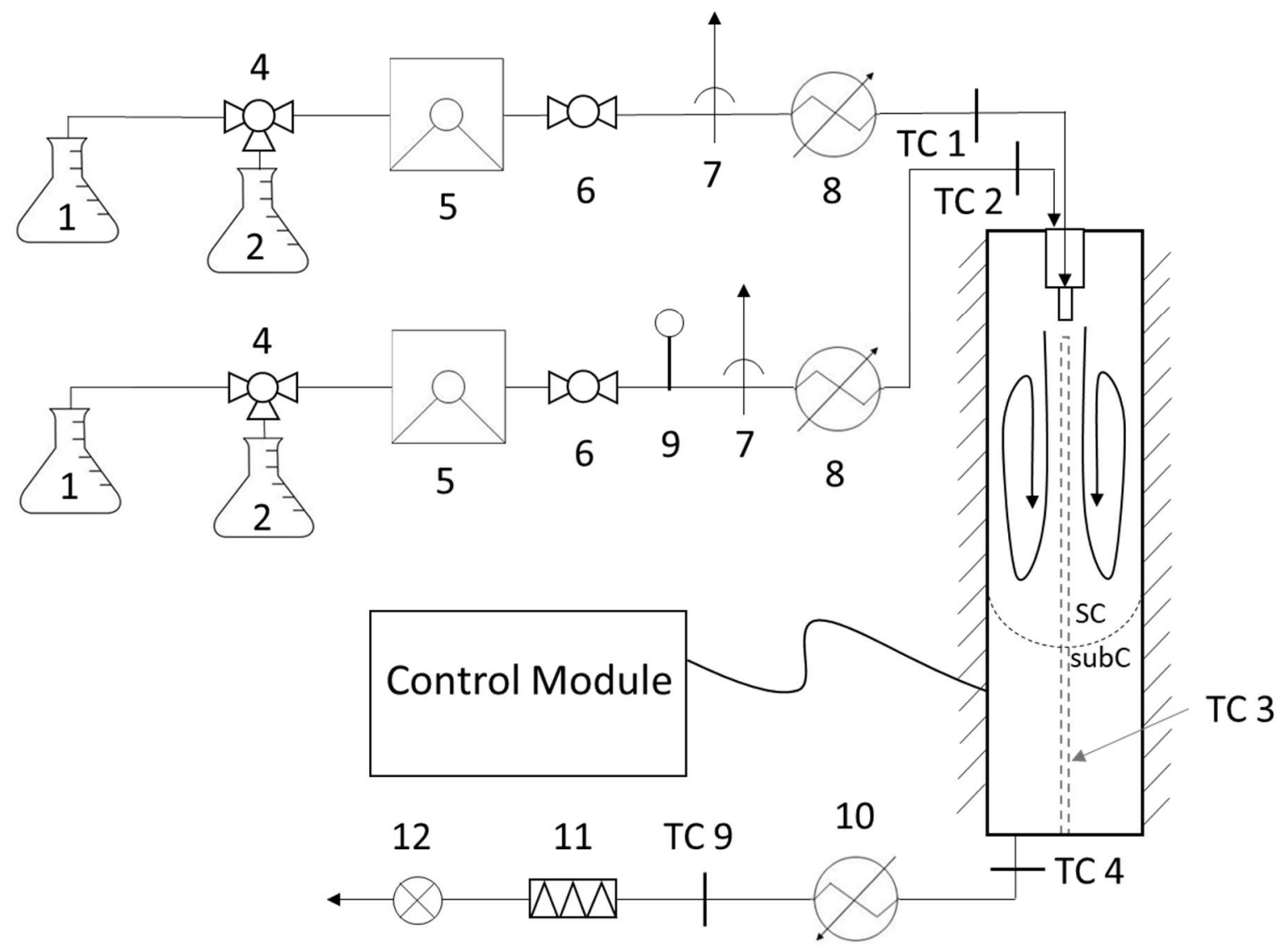

Figure 1: Schematic of SCWO reactor. Components include 1) dilute ethanol; 2) $\mathrm{DI}_{2} \mathrm{O}$; 3$) 30 \mathrm{wt} \% \mathrm{H}_{2} \mathrm{O}_{2}$; 4) solenoid valves; 5) HPLC pumps; 6) on/off ball valves; 7) rupture disks; 8) $1 \mathrm{~kW}$ cartridge heaters; 9) pressure gauges; 10) $2 \mathrm{~kW}$ cooler; 11) $5 \mu \mathrm{m}$ filter; and 12) back-pressure regulator. Thermocouple locations include TC 1) fuel line; TC 2) oxidant line; TC 3) reactor section; TC 4) reactor fluid bottom; TC 5) reactor exit.

The reactor section is a titanium-lined vessel, with an internal volume of $\sim 1120 \mathrm{~mL}$. The titanium liner has an inner diameter (ID) of $24.25 \mathrm{~mm}$ and sits within a stainless steel 316 (SS316) outer tube with an ID of $25.4 \mathrm{~mm}$ and an outer diameter (OD) of $38.1 \mathrm{~mm}$. Reagents are injected into the reactor through a custom, co-axial nozzle at the top of the reactor, the details are shown in Figure 2. The nozzle is designed to create a SCWO reaction envelope, bound by the diffusive mixing of the oxidant and the fuel. Three fuse-welded Inconel 625 spacers center the fuel line within the oxidant line, as shown in Figure $2 \mathrm{~b}$. The fuel line protrudes $1.5 \mathrm{~mm}$ from the oxidant 
line, similar to the reported designs. ${ }^{26,27}$ The nozzle is constructed from Inconel 625, a nickel-base alloy commonly used in SCWO systems for resistance to oxidative corrosion and good structural performance at elevated temperatures. Reactor dimensions were determined based on commercially available tubing and fittings rated to the operational temperatures and pressures.

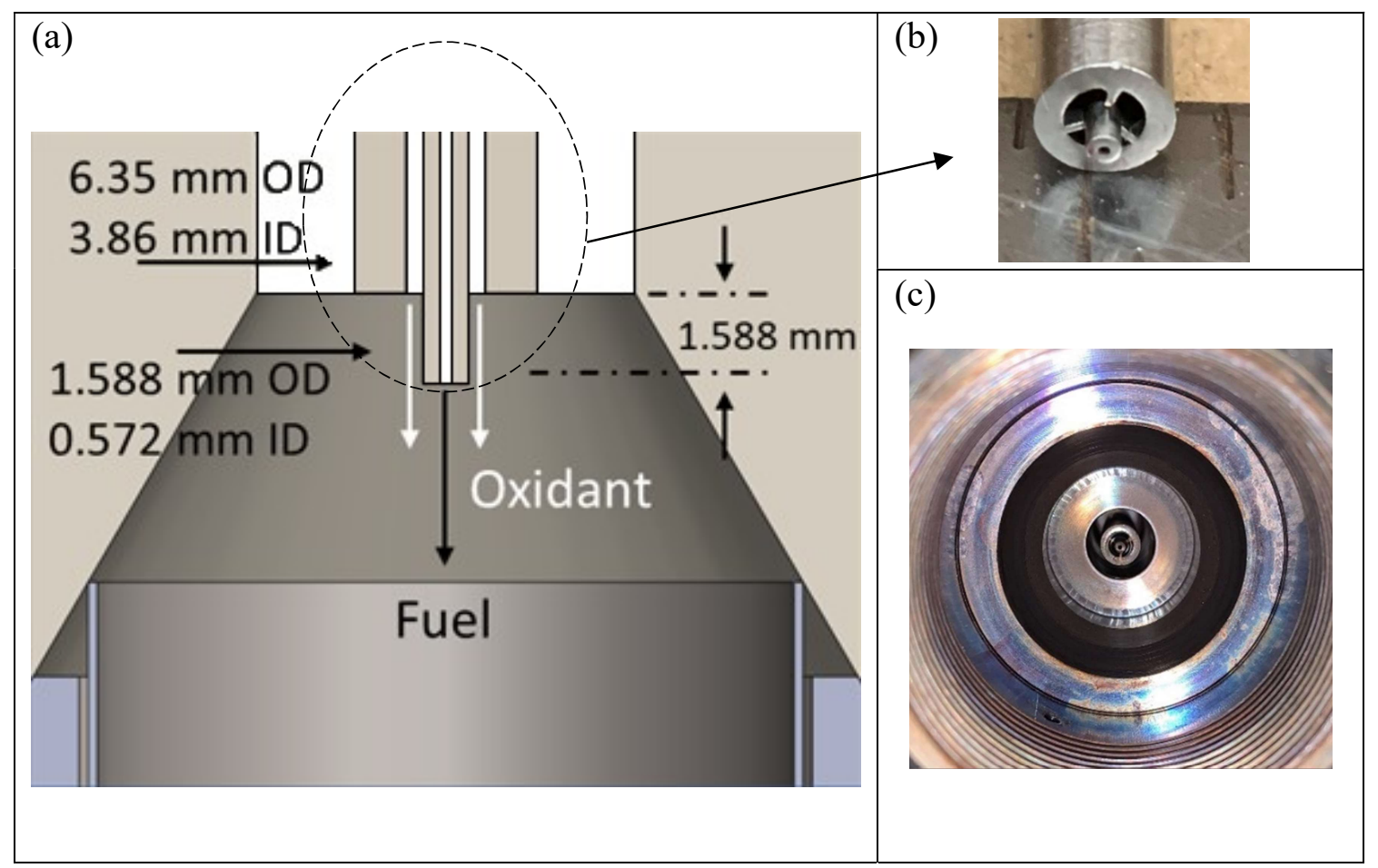

Figure 2: Design of the fuel/oxidant co-axial injector nozzle, showing a) geometry and dimensions, b) fuel line is centred within the oxidant line by three supports, and c) picture of fuel line mounted within the top of the main reactor section

After passing through the reactor section, the effluent is quenched through a heat exchanger and subsequently throttled across a back-pressure regulator (BPR), which is used to control the internal pressure. Additional information regarding the components used in the system and the overall design effort can be found elsewhere. ${ }^{31}$ 


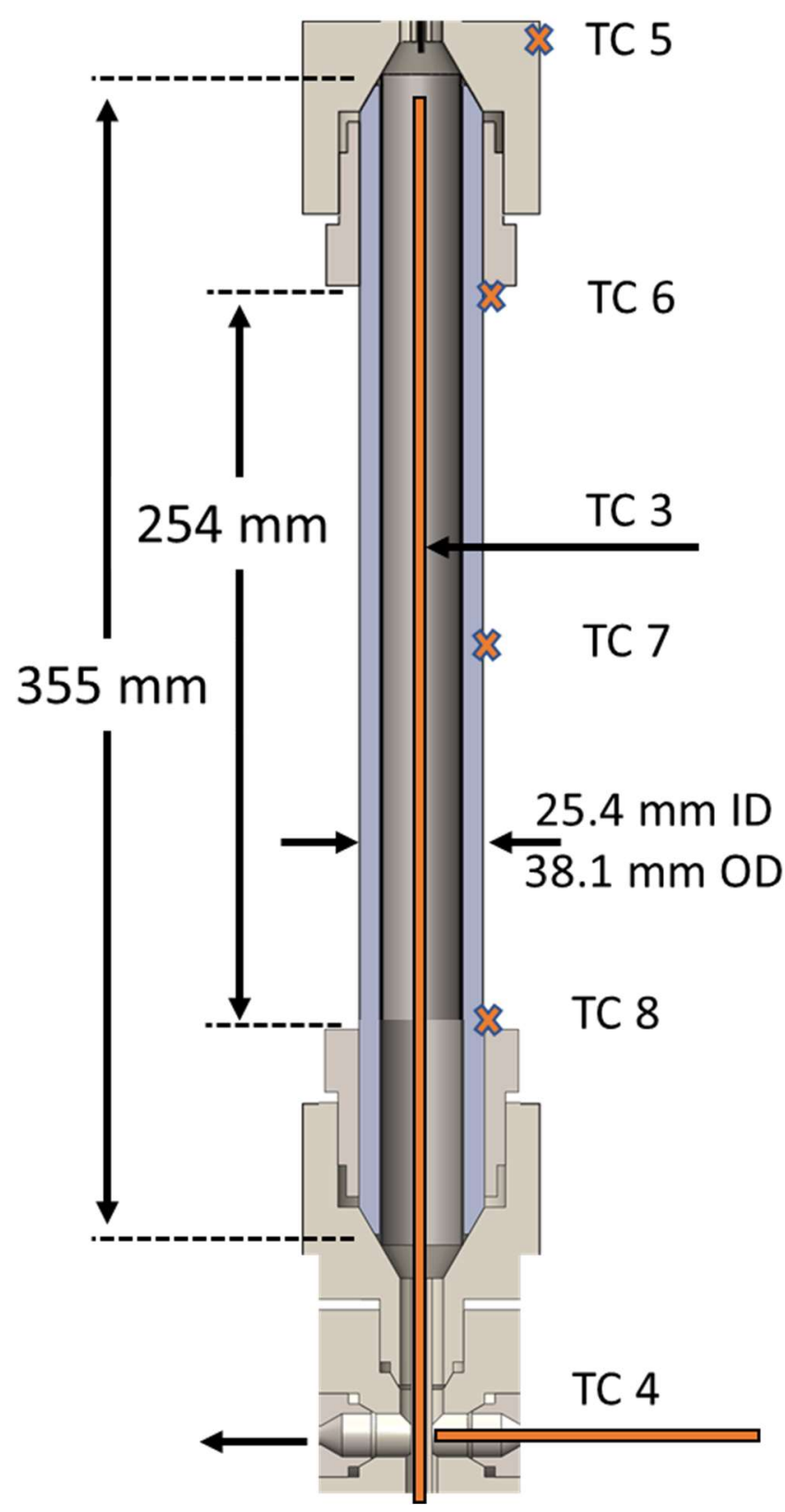

Figure 3: SCWO reactor section with locations of thermocouples used for reactor characterization and model validation. TCs 1 through 4 measure internal fluid temperatures while TCs 5 through 8 measure external wall temperatures. Not shown: TC 1 (fuel line) and TC 2 (oxidant line), located upstream of the nozzle. TC 5) nozzle wall; TC 6) reactor wall top; TC 7) reactor wall mid; TC 8) reactor wall bottom. 


\section{Reagent Purity and Preparation.}

DI water $(\rho=18.2 \mathrm{M}-\Omega)$ is used for all experiments. Aqueous $\mathrm{H}_{2} \mathrm{O}_{2}(30 \mathrm{wt} \%$ ACS Reagent Grade, Fisher Scientific) is used as the oxidant source. Reagent grade ethanol (99.8\%, Fisher Scientific) is diluted with DI water to the molarities indicated in Table 1 and is used as the pilot fuel for all experiments.

Table 1: Initial premixed fuel concentrations and resulting overall reactor fuel concentrations.

\begin{tabular}{|c|c|c|c|c|}
\hline \multicolumn{2}{|c|}{ Premixed Fuel Concentration } & \multicolumn{3}{|c|}{ Overall Species Concentrations Introduced to Reactor } \\
\hline \%mol EtOH & $\%$ mol $\mathrm{H}_{2} \mathrm{O}$ & \%mol EtOH & $\% \mathrm{~mol} \mathrm{H}_{2} \mathrm{O}$ & $\% \mathrm{~mol} \mathrm{O}_{2}$ \\
\hline 2 & 98 & 1.2 & 95.4 & 3.35 \\
\hline 3 & 97 & 1.53 & 94.26 & 4.21 \\
\hline 4 & 96 & 1.76 & 93.4 & 4.83 \\
\hline 5 & 95 & 1.93 & 92.78 & 5.29 \\
\hline 6 & 94 & 2.06 & 92.29 & 5.66 \\
\hline 7 & 93 & 2.17 & 91.89 & 5.95 \\
\hline
\end{tabular}

\section{Oxidant Source.}

As shown in Figure 1, the aqueous $\mathrm{H}_{2} \mathrm{O}_{2}$ is preheated prior to injection, to a temperature between $400{ }^{\circ} \mathrm{C}$ and $425{ }^{\circ} \mathrm{C} . \mathrm{H}_{2} \mathrm{O}_{2}$ is known to decompose to $\mathrm{H}_{2} \mathrm{O}$ and $\mathrm{O}_{2}$ within $\mathrm{SCW}$, with a first-order rate expression determined by Croiset, Rice and Hanush as:

$$
k_{g}\left(s^{-1}\right)=10^{13.9 \pm 0.07} \exp \left[\left(-182 \pm 1 \frac{k J}{m o l}\right) / R T\right]
$$

where $T$ is expressed in Kelvin for purposes of the equation, based on directly observed $k_{g}$ values of $1.17 \pm 0.09 \mathrm{~s}^{-1}$ and $2.42 \pm 0.57 \mathrm{~s}^{-1}$ at $400{ }^{\circ} \mathrm{C}$ and $425^{\circ} \mathrm{C}$, among others. ${ }^{32}$ At a preheat temperature of $400{ }^{\circ} \mathrm{C}, \mathrm{H}_{2} \mathrm{O}_{2}$ is $99 \%$ decomposed to $\mathrm{H}_{2} \mathrm{O}$ and $\mathrm{O}_{2}$ after $3.94 \mathrm{~s}$ in the preheater. The oxidant is therefore assumed to enter as a supercritical mixture of $\mathrm{O}_{2}$ and $\mathrm{H}_{2} \mathrm{O}$, with most of the $\mathrm{H}_{2} \mathrm{O}_{2}$ decomposed before entering the reactor. Note that the prolonged use of $\mathrm{H}_{2} \mathrm{O}_{2}$ causes periodic pump failure, likely due to hydrodynamic cavitation and/or oxidation damaging the seals or checkvalves. The use of compressed air is more desirable for overall system longevity; however, the 
preheat and the flow control of compressed air presents a separated set of challenges and is not explored in this work.

\section{Data Collection and Analysis.}

The reactor section is well-insulated and instrumented with two internal Type-K thermocouples (TC 3, TC 4), and four external Type-K thermocouples (TCs 5 through 8), as shown in Error! Reference source not found. TC 3 is adjustable, and either positioned $25 \mathrm{~mm}$ or 178 $\mathrm{mm}$ from the reactor nozzle, with the position changed between runs to measure internal temperatures at two separate locations during operation at identical processing conditions. All influent lines are instrumented with internal Type-K thermocouples, shown in Error! Reference

source not found.. The thermocouples are monitored continuously during each experiment, allowing for characterization of the reactor thermal profile under steady-state operating conditions and thermal response time during dynamic operation. A representative temperature profile during an experimental run is shown in Figure S2. The cooled reactor effluent is periodically analyzed with a handheld Raman spectroscopic probe to verify complete oxidation of ethanol within the reactor; details of the Raman probe and analysis are provided in the Supporting Information.

\section{Experimental Conditions.}

The oxidant-to-fuel stoichiometric equivalence ratio $\left(\phi_{A F}\right)$ is defined as the percentage of molar oxygen introduced to the reaction environment, relative to the amount required for complete oxidation of the parent hydrocarbon to $\mathrm{CO}_{2}$ and $\mathrm{H}_{2} \mathrm{O}$. The expression for ethanol reaction with $\mathrm{H}_{2} \mathrm{O}_{2}$ follows:

$$
\mathrm{C}_{2} \mathrm{H}_{5} \mathrm{OH}+6 \mathrm{H}_{2} \mathrm{O}_{2} \rightarrow 9 \mathrm{H}_{2} \mathrm{O}+2 \mathrm{CO}_{2}
$$


With 6 mol $\mathrm{H}_{2} \mathrm{O}_{2}$ required for stoichiometric oxidation of $1 \mathrm{~mol}$ ethanol. When $\mathrm{H}_{2} \mathrm{O}_{2}$ is the oxidant source, $\phi_{A F}$ can be expressed as:

$$
\phi_{A F}=\frac{\dot{n}_{\mathrm{H}_{2} \mathrm{O}_{2}} / 6}{\dot{n}_{\text {ethanol }}}
$$

where $\dot{n}_{\mathrm{H}_{2} \mathrm{O}_{2}}$ is the molar flow rate of $\mathrm{H}_{2} \mathrm{O}_{2}$, and $\dot{n}_{\text {ethanol }}$ is the molar flow rate of ethanol.

Reynolds numbers $(R e)$ and flow velocities $(V)$ are calculated for both the fuel and oxidant lines, using conservation of mass, and fluid properties based on the fluid temperatures of $400{ }^{\circ} \mathrm{C}$ and pressure of $25 \mathrm{MPa}$. Plug flow assumptions are invalid for this reactor configuration due to the existence of the radial concentration gradients and buoyancy-driven recirculation zones. Despite this, nominal residence times are calculated using internal temperature measurements during operation (TC 1, TC 2, TC $3(25 \mathrm{~mm})$, TC $3(178 \mathrm{~mm})$, and TC 4), which are used to determine the local density of water at the measured temperature and pressure. Volumetric flow rates are calculated based on the local densities, and the average time for the fluid to travel between TCs is then determined by averaging the respective volumetric flow rates. The sum of these discretized residence times is referred to in Table 2 as the nominal residence time.

Table 2: Reynolds numbers and residence times for conditions corresponding to the tested fuel dilutions

\begin{tabular}{|c|c|c|c|c|c|c|c|c|}
\hline $\begin{array}{l}\text { Premixed Fuel } \\
\text { Concentration } \\
(\% \mathrm{~mol})\end{array}$ & $\phi_{A F}$ & $\begin{array}{l}\text { Nominal } \\
\text { Residence } \\
\text { Time } \\
\text { (s) }\end{array}$ & $\begin{array}{c}\text { Flow Rate } \\
\text { of Fuel } \\
\text { Pump } \\
\text { (mL/min) }\end{array}$ & $\begin{array}{c}\text { Flow Rate } \\
\text { of Oxidant } \\
\text { Pump } \\
\text { (mL/min) }\end{array}$ & $\begin{array}{c}V \text { of } \\
\text { Fuel at } \\
\text { Nozzle } \\
(\mathrm{m} / \mathrm{s})\end{array}$ & $\begin{array}{c}\text { Re of } \\
\text { Fuel at } \\
\text { Nozzle }\end{array}$ & $\begin{array}{c}V \text { of } \\
\text { Oxidant } \\
\text { at Nozzle } \\
(\mathrm{m} / \mathrm{s})\end{array}$ & $\begin{array}{c}\text { Re of } \\
\text { Oxidant } \\
\text { at } \\
\text { Nozzle }\end{array}$ \\
\hline 2 & 1.1 & 17.6 & 13.8 & 10 & 8.16 & 17449 & 0.17 & 2090 \\
\hline \multirow{2}{*}{3} & 1.1 & 21 & 9.4 & 10 & 5.52 & 11809 & 0.17 & 2090 \\
\hline & 1.5 & 31.5 & 6.9 & 10 & 4.04 & 8660 & 0.17 & 2090 \\
\hline \multirow{2}{*}{4} & 1.1 & 23.2 & 7.2 & 10 & 4.20 & 8986 & 0.17 & 2090 \\
\hline & 1.5 & 32.3 & 5.3 & 10 & 3.08 & 6592 & 0.17 & 2090 \\
\hline \multirow{2}{*}{5} & 1.1 & 25 & 5.9 & 10 & 3.41 & 7296 & 0.17 & 2090 \\
\hline & 1.5 & 32.3 & 4.3 & 10 & 2.50 & 5351 & 0.17 & 2090 \\
\hline \multirow{2}{*}{6} & 1.1 & 25.1 & 5.0 & 10 & 2.88 & 6168 & 0.17 & 2090 \\
\hline & 1.5 & 30.4 & 3.7 & 10 & 2.11 & 4523 & 0.17 & 2090 \\
\hline \multirow{2}{*}{7} & 1.1 & 25.3 & 4.4 & 10 & 2.51 & 5363 & 0.17 & 2090 \\
\hline & 1.5 & 29.9 & 3.2 & 10 & 1.84 & 3933 & 0.17 & 2090 \\
\hline
\end{tabular}




\section{Results \& Discussion}

\section{Effect of Oxidant Concentration on Temperature Profiles.}

The reactor is operated at $\phi_{A F}$ of 1.1 and 1.5 using the pump flow rates presented in Table 2 to study the effect of excess oxidant on system performance. At higher fuel percentages, increased $\phi_{A F}$ leads to larger temperature fluctuations denoted by the increasing standard deviation in Figure 4. At higher $\phi_{A F}$, lower overall temperatures are observed due to the diluent effect of the excess oxidant.

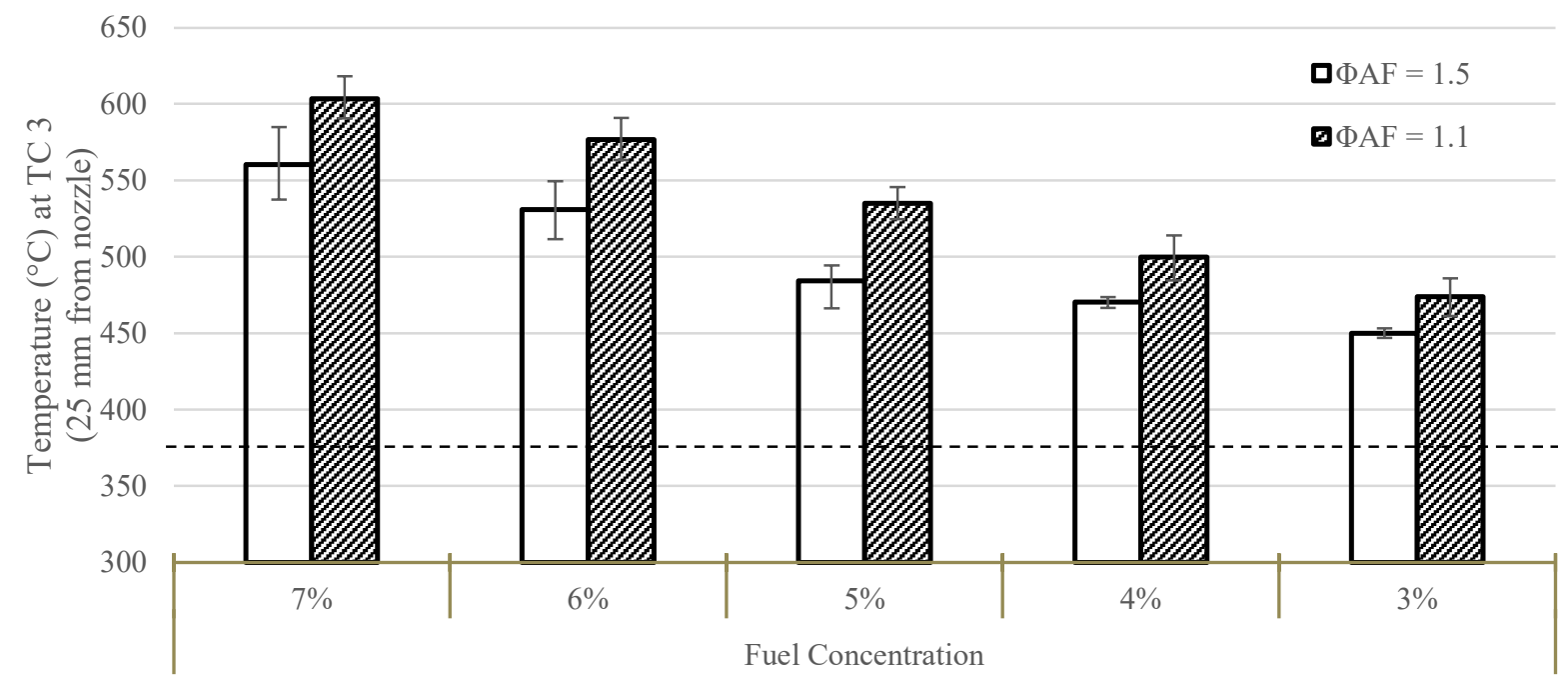

Figure 4: Reactor temperatures measurements as a function of $\phi_{A F}$ and varied fuel concentration. TC 3 is positioned $25 \mathrm{~mm}$ from the nozzle. The dashed line indicates the critical temperature $\left(374{ }^{\circ} \mathrm{C}\right)$.

\section{Effect of Premixed Fuel Dilution on Temperature Profiles.}

Figure 5 shows the effect of initial ethanol dilution on the internal temperatures achieved within the SCWO reactor, with $\phi_{A F}$ held constant at 1.1 . Previous work has shown that $600{ }^{\circ} \mathrm{C}$ is 
a suitable temperature for complete destruction of a CWA while operating within the safe material limits for reactor walls. ${ }^{10}$ Although fuel concentration is varied, flow rates are adjusted to ensure constant fuel heating value into the reactor (Error! Reference source not found.). Internal temperature measurements are collected under steady-state operation. At least two reactor runs are performed for each condition with TC 3 positioned $25 \mathrm{~mm}$ or $178 \mathrm{~mm}$ from the fuel nozzle. These measurements allow profiling the axial temperature distribution within the reactor. The effluent and wall measurements are found to be in good agreement between runs. Higher fuel concentration results in a greater axial temperature gradient and an increase in the maximum measured temperature near the fuel inlet. The fluid temperature near the middle of the reactor shows no significant correlation between temperature and fuel concentration, and the exit temperatures for high fuel concentration runs had the lowest measured temperature. 


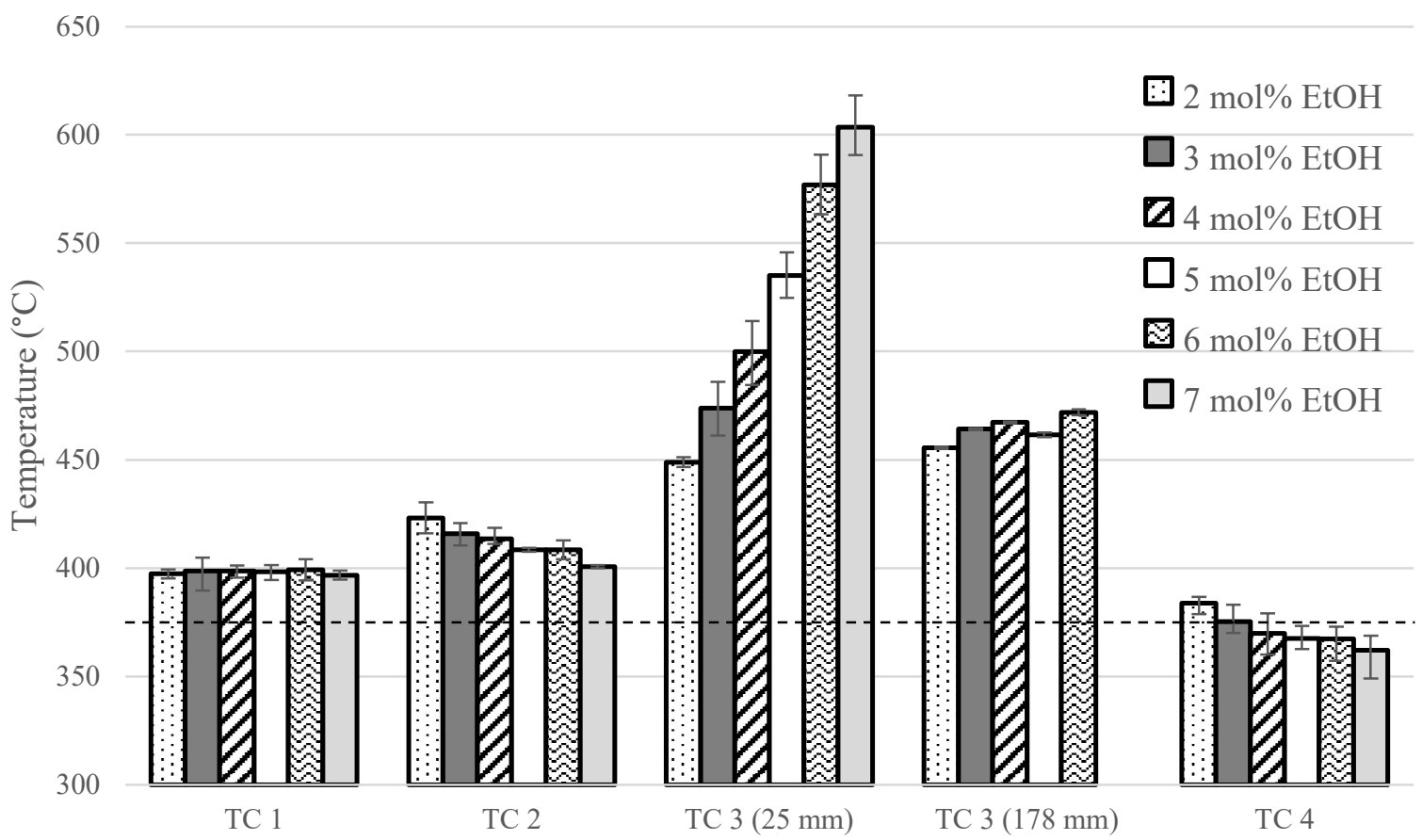

Figure 5: Thermocouple measurements during steady-state operation with $\Phi_{\mathrm{AF}}=1.1$ and varying concentrations of ethanol. TC 3 is used to measure steady-state temperatures at two separate locations during two separate runs. Dashed line represents the critical temperature $\left(374^{\circ} \mathrm{C}\right)$.

We surmise that increasing the fuel concentration shifts the oxidizing zone upstream; the fuel is consumed more rapidly, leading to higher local temperatures. The high vertical temperature gradient has a positive gain effect as the buoyancy further amplifies the temperature stratification leading to faster reaction rates near the top of the reactor. The slow kinetics and the higher overall flow rates for the cases with lower fuel concentration show a more distributed reaction region and reduce the effect of buoyancy. This is analogous to operating combustion systems, which become more uniform at conditions when the flames velocities are reduced or reactor loading increases. ${ }^{33,34}$ CFD simulations confirm that increasing fuel concentration shifts the primary reacting zone 
toward the top of the reactor, which is discussed in Part II of this work. The liquid effluent from all conditions is shown by Raman spectroscopy to contain no remaining ethanol, as presented in Figure S1.

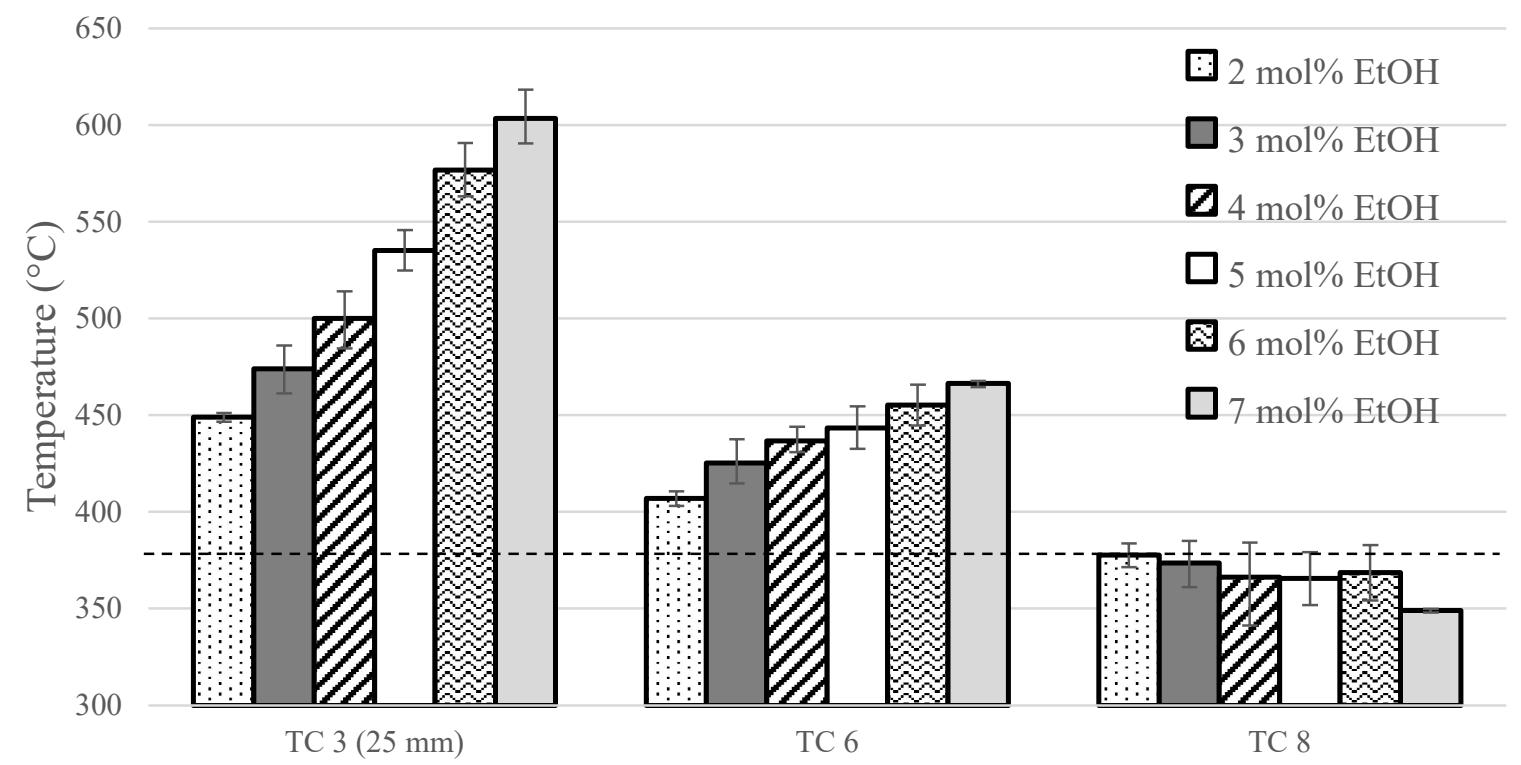

Figure 6: External reactor wall temperatures (TC 6 and TC 8) at varied fuel dilutions and constant $\Phi_{\mathrm{AF}}=1.1$ with internal reactor temperature (TC 3 ) for reference.

During operation, the external wall temperature follows the same trends observed for internal fluid temperatures. At the top of the reactor (TC 6), the reactor wall temperatures increase with the onset of the SCWO reaction (Figure 5Figure 6). The reactor wall bottom temperatures decrease following fluid temperature trends (Figure 5). Although the maximum fluid temperatures increased by an average of $31.9{ }^{\circ} \mathrm{C} / \mathrm{mol} \%$ ethanol, the wall temperatures increased only by an average of $11.9^{\circ} \mathrm{C} / \mathrm{mol} \%$ ethanol. Reactor walls are rated to $600{ }^{\circ} \mathrm{C}$ due to the significant decrease in the tensile strength of SS316 at elevated temperatures. Though the fluid temperatures exceeded 
$600^{\circ} \mathrm{C}$, reactor wall temperatures never rose above $468^{\circ} \mathrm{C}$, showing the feasibility of achieving conditions suitable for the destruction of the CWA and other hazardous wastes.

A CFD model of this SCWO reactor is validated using these results and is discussed in Part II. The experimental insight into the kinetics, coupled with the validated CFD model, will allow future work towards optimizing the nozzle and reactor geometry, tuning operational parameters to ensure safe operation and complete waste destruction.

\section{Conclusions}

A small-scale, downward-flow SCWO reactor is designed and characterized under varied fuel and oxidant flow rates. The reactor fluid temperature of $600{ }^{\circ} \mathrm{C}$ and corresponding residence time of $25.3 \mathrm{~s}$ is achieved with $7 \mathrm{~mol} \%$ ethanol as the pilot fuel and $30 \mathrm{wt} \% \mathrm{H}_{2} \mathrm{O}_{2}$ as the oxidant at $\phi_{A F}=1.1$. These conditions are well-suited to destroy most hazardous wastes. Maximum temperatures are observed immediately downstream of the injection nozzle at highest fuel concentrations. However, fluid temperature downstream does not change significantly with fuel dilution. We infer that faster heat release and buoyancy effects increases the local temperature at the top of the reactor. Reactor characterization can be used to validate CFD models for reactor optimization. Relatively low reactor wall temperatures during operation of $7 \mathrm{~mol} \%$ ethanol suggests possible operation with higher premixed fuel concentrations. When operating with $\mathrm{H}_{2} \mathrm{O}_{2}$, the maximum local temperature is observed at $\phi_{A F}=1.1$. Operating at the lower dilution leads to a more uniform temperature profile as the reaction approached the distributed reaction region. 


\section{ASSOCIATED CONTENT}

\section{Supporting Information}

The following files are available free of charge at:

https://pubs.acs.org/doi/10.1021/XXX.

- Figure of collected Raman spectrum of typical reactor effluent, table containing average temperature measurements for each thermocouple at each condition, and a plot of the typical reactor temperature profile over the course of a full experimental run (PDF)

\section{AUTHOR INFORMATION}

\section{Corresponding Author}

*ivn@uw.edu; +1 206 543-5248; ORCID: 0000-0002-6347-7450

\section{Author Contributions}

The manuscript was written through contributions of all authors. All authors have given approval to the final version of the manuscript.

\section{Funding Sources}

Funding for this work was provided by Defense Threat Reduction Agency (DTRA) - Grant HDTRA1-17-1-0001 and a Cooperative Research and Development Agreement (CRADA) with the Army Research Office (ARO) - Project Number CB10397.

\section{ACKNOWLEDGMENTS}


Funding for this work was provided by Defense Threat Reduction Agency (DTRA) - Grant

HDTRA1-17-1-0001 and a Cooperative Research and Development Agreement (CRADA) with the Army Research Office (ARO) - Project Number CB10397. Special thanks to Byron Ockerman and Tim Wallace for assistance with reactor fabrication and operation.

\section{ABBREVIATIONS}

CFD, computational fluid dynamics; CWA, chemical warfare agent; DI, deionized; DTRA, Defense Threat Reduction Agency; EtOH, ethanol; ID, inner diameter; OD, outer diameter; SCW, supercritical water; SCWO, supercritical water oxidation; SC, supercritical; SS316, Stainless Steel 316; subC, subcritical; TC, thermocouple

\section{REFERENCES}

[1] Gidner, A.; Stenmark L. Supercritical water oxidation of sewage sludge - State of the art. Proceedings of the IBC's Conference on Sewage Sludge and Disposal Options 2001.

[2] Goto, M.; Nada, T.; Kodama A.; Hirose, T. Kinetic analysis for destruction of municipal sewage sludge and alcohol distillery wastewater by supercritical water oxidation. Ind. Eng. Chem. Res. 1999, 38, 1863-1865. https://doi.org/10.1021/ie980479s.

[3] Patterson, D. A.; Stenmark, L.; Hogan, F. In Pilot-scale supercritical water oxidation of sewage sludge, Presented at the 6th European Biosolids and Organic Residuals Conference, 2001, 14.

[4] Svanström, M.; Fröling, M.; Modell, M.; Peters, W. A.; Tester, J. Environmental assessment of supercritical water oxidation of sewage sludge. Resour. Conserv. Recycl. 2004, 41, 321-338. https://doi.org/10.1016/j.resconrec.2003.12.002. 
[5] Xu, D.; Wang, S.; Tang, X.; Gong, Y.; Guo, Y.; Wang, Y. Design of the first pilot scale plant of China for supercritical water oxidation of sewage sludge. Chem. Eng. Res. Des. 2012, 90, 288-297. https://doi.org/10.1016/j.cherd.2011.06.013.

[6] Baur, S.; Schmidt, H.; Krämer, A.; Gerber, J. The destruction of industrial aqueous waste containing biocides in supercritical water - development of the SUWOX process for the technical application. J. Supercrit. Fluids 2005, 33, 149-157.

https://doi.org/10.1016/j.supflu.2004.07.005.

[7] Bermejo, M. D.; Cocero, M. J. Destruction of an industrial wastewater by supercritical water oxidation in a transpiring wall reactor. J. Haz. Mat. 2006, 137, 965-971. https://doi.org/10.1016/j.jhazmat.2006.03.033.

[8] Cocero, M. Supercritical Water Oxidation. Application to Industrial Waste Water Treatment. High Pressure Process Technology: Fundamentals and Applications. A. Bertuco, G. Vetter Eds. Elsevier, 2000.

[9] Yang, J.; Wang, S.; Li, Y.; Zhang, Y.; Xu, D. Novel design concept for a commercialscale plant for supercritical water oxidation of industrial and sewage sludge. J. Environ. Manage. 2019, 233, 131-140. https://doi.org/10.1016/j.jenvman.2018.11.142.

[10] Bianchetta, S.; Li, L.; Gloyna, E. F. Supercritical Water Oxidation of Methylphosphonic Acid. Ind. Eng. Chem. Res. 1999, 38, 2902-2910. https://doi.org/10.1021/ie990094p.

[11] National Academies of Sciences, Engineering, and Medicine. Metrics for Successful Supercritical Water Oxidation System Operation at the Blue Grass Chemical Agent 
Destruction Pilot Plant. The National Academics Press, Washington

DC 2019. https://doi.org/10.17226/25390.

[12] Marrone, P. A.; Cantwell, S. D.; Dalton, D. W. SCWO system designs for waste treatment: Application to chemical weapons destruction. Ind. Eng. Chem. Res. 2005, 44, 9030-9039. https://doi.org/10.1021/ie0506670.

[13] Veriansyah, B.; Kim, J.-D.; Lee, J.-C. Destruction of chemical agent simulants in a supercritical water oxidation bench-scale reactor. J. Haz. Mat. 2007, 147, 8-14. https://doi.org/10.1016/j.hazmat.2006.12.040.

[14] Veriansyah, B.; Song, E.-S.; Kim, J.-D. Destruction of methylphosphonic acid in a supercritical water oxidation bench-scale double wall reactor. J. Environ. Sci. 2011, 23, 545-552. https://doi.org/10.1016/S1001-0742(10)60446-9.

[15] Bermejo, M. D.; Rincon, D.; Martin, A.; Cocero, M. J. Experimental performance and modeling of a new cooled-wall reactor for the supercritical water oxidation. Ind. Eng. Chem. Res. 2009, 48, 6262-6272. https://doi.org/10.1021/ie900054e.

[16] Schlueb, M. Reactor blowout sidelines Orlando's waste-to-energy hopes. Orlando Sentinel 2014, accessed June 23, 2020 (https://www.orlandosentinel.com/news/os-xpm2014-03-15-os-orlando-reactor-blow-out-20140315-story.html).

[17] Clark, J., Orange County Sanitation District Biosolids Master Plan. In Technical Memorandum No. 9: Aqua Critox Review - OCSD Project No. PS15-01, Orange County Sanitation District, 2017, 9. 
[18] Tang, X.; Wang, S.; Qian, L.; Li, Y.; Lin, Z.; Xu, D.; Zhang, Y. Corrosion behavior of nickel base alloys, stainless steel and titanium alloy in supercritical water containing chloride, phosphate and oxygen. Chem. Eng. Res. Des. 2015, 100, 530-541. https://doi.org/10.1016/j.cherd.2015.05.003.

[19] Marrone, P. A.; Hong, G. T. Corrosion control methods in supercritical water oxidation and gasification processes. J. Supercrit. Fluids 2009, 51, 83-103. https://doi.org/10.1016/j.supflu.2009.08.001.

[20] Marrone, P. A.; Hodes, M.; Smith, K. A.; Tester, J. W. Salt precipitation and scale control in supercritical water oxidation-part B: commercial/full-scale applications. $J$. Supercrit. Fluids 2004, 29, 289-312. https://doi.org/10.1016/S0896-8446(03)00092-5.

[21] Pinkard, B. R.; Gorman, D. J.; Tiwari, K.; Rasmussen, E. G.; Kramlich, J. C.; Reinhall, P. G.; Novosselov, I. V. Supercritical water gasification: practical design strategies and operational challenges for lab-scale, continuous flow reactors. Heliyon 2019, 5, e01269. https://doi.org/10.1016/j.heliyon.2019.e01269.

[22] Davis, J.; Tiwari, K.; Novosselov, I., Soot morphology and nanostructure in complex flame flow patterns via secondary particle surface growth. Fuel 2019, 245, 447-457. https://doi.org/10.1016/j.fuel.2019.02.058.

[23] Chakrabarty, R. K.; Novosselov, I. V.; Beres, N. D.; Moosmüller, H.; Sorensen, C. M.; Stipe, C. B., Trapping and aerogelation of nanoparticles in negative gravity hydrocarbon flames. $\quad$ Applied Physics Letters 2014, $104 \quad$ (24), 243103. https://doi.org/10.1063/1.4884057. 
[24] Mahamuni, G.; Rutherford, J.; Davis, J.; Molnar, E.; Posner, J. D.; Seto, E.; Korshin, G.; Novosselov, I., Excitation-Emission Matrix Spectroscopy for Analysis of Chemical Composition of Combustion Generated Particulate Matter. Environ. Sci. Technol. 2020, 54 (13), 8198-8209. https://doi.org/10.1021/acs.est.0c01110.

[25] Davis, J.; Molnar, E.; Novosselov, I., Nanostructure transition of young soot aggregates to mature soot aggregates in diluted diffusion flames. Carbon 2020, 159, 255-265. https://doi.org/10.1016/j.carbon.2019.12.043.

[26] Hicks, M. C.; Hegde, U. G.; Kojima, J. J. Hydrothermal ethanol flames in Co-flow jets, $J$. Supercrit. Fluids 2019, 145, 192-200. https://doi.org/10.1016/j.supflu.2018.12.010.

[27] Serikawa, R. M.; Usui, T.; Nishimura, T.; Sato, H.; Hamada, S.; Sekino, H. Hydrothermal flames in supercritical water oxidation: investigation in a pilot scale continuous reactor. Fuel 2002, 81, 1147-1159. https://doi.org/10.1016/S0016-2361(02)00015-7.

[28] Steeper, R. R.; Rice, S. F.; Brown, M. S.; Johnston, S. C., Methane and methanol diffusion flames in supercritical water. The Journal of Supercritical Fluids 1992, 5 (4), 262-268. https://doi.org/10.1016/0896-8446(92)90017-E.

[29] Hazlebeck, D. A.; Downey, K. W.; Spritzer, M. H., Downflow hydrothermal treatment. Google Patents: 2000.

[30] Pinkard, B. R.; Kramlich, J. C.; Novosselov, I. V. Gasification Pathways and Reaction Mechanisms of Primary Alcohols in Supercritical Water. ACS Sustain. Chem. Eng. 2020, 8, 4598-4605. https://doi.org/10.1021/acssuschemeng.0c00445. 
[31] Moore, S. J. Design, Fabrication, and Operational Parameters of a Supercritical Water Oxidation Reactor, University of Washington, Ann Arbor, 2020. ProQuest, https://search.proquest.com/docview/2436911967?accountid=14784.

[32] Croiset, E.; Rice, S. F.; Hanush, R. G. Hydrogen Peroxide Decomposition in Supercritical Water. AIChE J. 1997, 43, 2343-2352. https://doi.org/10.1002/aic.690430919.

[33] Guan, Y.; Novosselov, I., Damkohler Number Analysis in Lean Blow-Out of Toroidal Jet Stirred Reactor. J Eng Gas Turbine Power 2018, 140 (10), 104501. https://doi.org/10.1115/1.4040091.

[34] Karalus, M. F.; Fackler, K. B.; Novosselov, I. V.; Kramlich, J. C.; Malte, P. C. In Characterizing the mechanism of lean blowout for a recirculation-stabilized premixed hydrogen flame, ASME Turbo Expo 2012: Turbine Technical Conference and Exposition, American Society of Mechanical Engineers: 2012; pp 21-30. 